\title{
Advances in Rheological Measurement of Drilling Fluid-A Review
}

\author{
Yogita Weikey*, Shobha Lata Sinha and Satish Kumar Dewangan \\ National Institute of Technology, India \\ *Corresponding author: Yogita Weikey, National Institute of Technology, Raipur, India.
}

Submission: 㘹 February 16, 2018; Published: 眥 May 22, 2018

\begin{abstract}
The present review paper discusses the various advances in rheological measurement in drilling fluid. In drilling industries, there are high and extremely high shear rate ranges in which several practical processes require knowledge of rheological behavior of materials under such conditions. Many experimental techniques have been reviewed based on the past researches and recent advances made in this field.
\end{abstract}

\section{Introduction}

For optimized drilling the most important variable to be considered is drilling fluid [1,2]. This means that drilling fluid should possess suitable properties as required for particular drilling operation. The properties of a given drilling fluid are defined by term mud rheology. The flow properties of drilling fluid, selection of operating conditions for optimized drilling, hole-cleaning, wellbore stability etc., depend on suitable rheology of drilling fluid. Rheology is the science of the flow and deformation under the effect of an applied force. It plays important role in drilling fluid preparation. The important key rheological characteristics of fluid that affect drilling fluid are plastic viscosity, apparent viscosity, effective viscosity, gel strength and yield point. Depending on the rheology, fluids can be classified as Newtonian or non-Newtonian. Almost all the drilling fluids confirm non-Newtonian behavior.

For Newtonian fluid, shear rate is proportional to the shear stress i.e. viscosity has a constant value. Water, glycerin and oil are examples of Newtonian fluids. Pseudo-plastic fluids have no yield point. A power-law fluid is an example pseudo-plastic fluid. Suspensions of long chain polymers are examples of typical pseudoplastics fluids. For better hole cleaning, the drilling fluids should be shear thinning [3]. Bingham-plastic fluids will not flow until a shear stress is applied which is greater than the yield to start movement. When fluid starts to flow the curve becomes linear, and the slope is called the plastic viscosity. Oil well drilling fluids, cement slurries, etc. are examples of Bingham-plastic fluids.

Drilling fluids used in the oil and gas industry usually comprise of either non-Newtonian pseudo-plastic or yield pseudo-plastic fluids. There is no single rheological mathematical model which can exactly fit the shear stress-shear rate data of all drilling fluids. There have been other models proposed by researchers in past few years [4-6] done parametric analysis for the rheological models, such as the Bingham plastic, power law and yield-pseudo-plastic models. Borg \& Paakkonen [7] proposed model which presents viscoelastic formulas for shear viscosity and other types of flow. Furthermore, many recent advances of tools and sensors are developed for finding various parameters of drilling fluid rheology. Some researcher used different models for describing the behavior of water based drilling fluid. Kelessidis \& Maglione [8] used two and three-parameter rheological models to determine to describe the rheology of aqueous bentonite suspensions and found that both models describe well the experimental data of these bentonite suspensions with good statistical indicators. Kelessidis et al. [9] described drilling fluids containing bentonite and bentonite lignite as additives by the three parameter rheological model and found that they provide non-optimal and even unrealistic solutions, which could be detrimental to the estimation of hydraulic parameters during drilling.

\section{Rheometry}

The constitutive equation can predict the material rheological properties when subject to stress, but one needs a set of experiments to measure such properties and test such prediction. Measurement of the rheological material functions is called rheometry. A rheometer is that device used to measure fluid parameters. The word rheometer can be of different type depending on geometry such as concentric cylinder, cone and parallel plate, or it may refer to a specific instrument for achieving such deformation. Simulation of rotational viscometer data of non-Newtonian fluids appears to be better when a larger number of rheological parameters are used. Many recent advances of tools and sensors are developed for finding various parameters of drilling fluid rheology. A viscometer 
is used to measure the viscosity of a fluid. It measures viscosity under one flow condition. For drilling fluids with viscosities that vary with flow conditions, an instrument called a rheometer is used. There are two different types of rheometers.

\section{Rotational or shear rheometers}

\section{Extensional rheometers}

Rheometers that control the applied shear stress are called rotational or shear rheometers, whereas rheometers that apply extensional stress or extensional strain are extensional rheometers. Rotational or shear-type rheometers are usually designed as either a native strain-controlled instrument which operates by controlling and applying a user-defined shear strain, and then measuring the resultant shear stress or a native stress controlled instrument which operates by controlling and applying a user-defined shear stress and measuring the resultant shear strain. Further the shear rheometer is classified into:

\section{Pipe or capillary \\ 2. Rotational cylinder \\ 3. Cone and plate \\ 4. Linear shear \\ 5. Annular flow}

Rotational type rheometers are widely used to determine the flow character of drilling fluids in the oil and gas industry. It is difficult to depend on such simplistic rheology measurements. Accurate determination of rheological parameters is difficult during complex drilling operations, where a correct calculation of the Equivalent Circulating Density (ECD) is vital. ECD management is possible using appropriate down-hole pressure measurement tools in combination with a good hydraulics model. However, even the best hydraulics model is only as good as its input parameters, and the parameters that matter the most are those associated with rheology. Continuous monitoring of drilling fluid rheology could result in prevention and/or early detection of some major drilling problems such as drilling fluid contamination, wellbore cleaning problems, wellbore instability, etc. Instead of having a more robust measurement technique that meets the current industry requirements, a newer automated version of the portable viscometer is introduced [10]. A pipe viscometer is available which is using sophisticated down-hole measurement technology that allows us to use the well itself as our measurement tool. As pipe has rotated, improvement in hole-cleaning has observed. Also, no bed development has observed as the inclination moved away from horizontal and pipe has rotated. Pipe viscometers often show better reliability and accuracy than rotational viscometers [11].

For viscosity reduction, the various methods provided by researcher are including preheating the crude oil, promoting the formation of oil-in-water emulsions, and adding drag reducing agents. Xu et al. [12] had carried out an experimental and theoretical study of drag reduction by gas injection for power-law fluid flow. A method for predicting the maximum drag reduction ratio was presented. The conclusions revealed that the stronger the shear thinning behavior of the fluids, the more significant the drag reduction was. Ashrafizadeh and Kamran [13] investigated the stability and viscosity of oil-in-water emulsions and their application for heavy oil pipeline transportation by using two Iranian crude oil samples. Their results showed that the emulsification reduced the viscosity of the crude oil, and the viscosity of the emulsions was increased by increasing the oil volume content and surfactant concentration. From laboratory and field tests, it was found that the combination of drilling fluid and rheology had a greater effect on the rate of penetration than any of the other controllable variables in the rotary drilling process. Many recent advances of tools and sensors are developed for finding various parameters of drilling fluid rheology.

\section{References}

1. Darley HCH, George GR (1988) Composition and properties of drilling and composition fluids. $\left(5^{\text {th }}\right.$ edn), Gulf professional publishing, Texas, USA.

2. Lummus JL, Barrett HM, Allen H (1953) The effects of use of oil in drilling muds. API Drill Prod Prac, pp. 135-145.

3. Mahto V, Sharma VP (2009) Tragacant gum: an effective oil well drilling fluid additive. Energy Sources 27(3): 299-308.

4. Bird RB, Dai GC, Yarusso BY (1982) The rheology and flow of viscoplastic materials. Rev Chem Eng 1(1): 1-70.

5. Kok MV, Gucuyener IH, Batmaz T (2002) End effect evaluation in rheological measurement of drilling fluids using couette coaxial cylinder viscometer. Energy Source 24(5): 441-449.

6. Kok MV, Batmaz T, Gucuyener IH (2000) Rheological behavior of bentonite suspensions. Pet Sci Tech 18(5-6): 519-536.

7. Borg T, Paakkonen EJ (2015) Linear viscoelastic model for different flows based on control theory. Appl Rheol 25(6).

8. Kelessidis VC, Maglione R (2006) Modeling rheological behavior of bentonite suspensions as casson and robertson-stiff fluids using newtonian and true shear rates in couette viscometry. Powder Technol 168(3): 134-147.

9. Kelessidis VC, Maglione R, Tsamantaki C, Aspirtakis Y (2006) Optimal determination of rheological parameters for herschel-bulkley drilling fluids and impact on pressure drop, velocity profiles and penetration rates during drilling. J Pet Sci Eng 53(3-4): 203-224.

10. Saasen A, Omland TH, Ekrene S, Breviere J, Villard E, et al. (2009) Automatic measurement of drilling fluid and drill-cuttings properties. Society of Petroleum Engineers 24(4).

11. Ahmed R, Miska S (2009) Advanced wellbore hydraulics. In: Aadnoy BS (Ed.), Advanced drilling and well technology. Society of Petroleum Engineers, USA, pp. 191-219.

12. Xu JY, Wu YX, Li H, Guo J, Chang Y (2009) Study of drag reduction by gas injection for power-law fluid flow in horizontal stratified and slug flow regimes. Chem Eng J 147(2-3): 235-244.

13. Ashrafizadeh SN, Kamran M (2010) Emulsification of heavy crude oil in water for pipeline transportation. J Pet Sci Eng 71(3-4): 205-211. 
Creative Commons Attribution 4.0 International License

For possible submissions Click Here

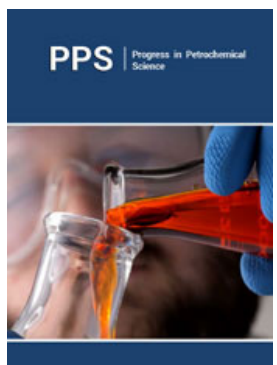

\section{Progress in Petrochemical Science}

\section{Benefits of Publishing with us}

- High-level peer review and editorial services

- Freely accessible online immediately upon publication

- Authors retain the copyright to their work

- Licensing it under a Creative Commons license

- Visibility through different online platforms 